\title{
UM ESTUDO SOBRE O CONCEITO DE HISTÓRIA E TEMPO PRESENTE EM MARX ATRAVÉS DA CRÍTICA DA ECONOMIA POLITICA DE 1859
}

\author{
Jean Paulo Pereira de Menezes ${ }^{1}$
}

\begin{abstract}
Resumo:
Esta comunicação está relacionada diretamente com o desenvolvimento de uma investigação em andamento pela Unesp de Marília a cerca do conceito de História e tempo presente na publicação de Karl Marx de 1859 intitulada Zur Kritik der Politschen Ökonomie. O objeto apresentado a seguir trata-se de um estudo teórico, classificado como bibliográfico-documental, localizado em meados do século XIX que busca o desenvolvimento de um estudo sobre o conceito de História e tempo presente em Marx, cronologicamente distante das formulações postuladas nos anos 1970 pelo Institut d'histoire du temps présent na França.
\end{abstract}

Palavras-chave: História, Economia Política, Grandes Narrativas

\begin{abstract}
:
This paper is directly related to an ongoing investigation which is being developed by Unesp Marilia concerning the concept of History and present time, found in a work written by Karl Marx in 1859 and entitled Zur Kritik der Politschen Ökonomie. The object shown hereinafter is a theoretical study, classified as bibliographical and documental, situated in the middle of the nineteenth century that seeks to develop a study concerning the concept of history and present time in Marx chronologically distant from the formulations postulated in the 1970s by the Institut d'histoire du temps présent in France.
\end{abstract}

Keywords: History, Political Economy, Grand Narratives

\section{Uma chave para a anatomia do macaco}

A proposta de intervenção textual que apresento aqui está relacionada diretamente o conceito de História e tempo presente na publicação de Karl Marx de 1859 intitulada Zur Kritik der Politschen Ökonomie (Para Crítica da Economia Política). O objeto apresentado a seguir não pretende se ocupar de um estudo situado no

\footnotetext{
${ }^{1}$ Doutorando em Ciências Sociais pela UNESP. Mestre em História pela UFGD. Docente do curso de Ciências Sociais da UNESP-Marília.
} 
tempo presente, tão pouco de entender Marx como historiador, menos ainda, um historiador do tempo presente. Trata-se de um estudo teórico, classificado como bibliográfico-documental, localizado em meados do século XIX. Entretanto, torna-se imprescindível levar em consideração o conceito de história do tempo presente desenvolvido durante o século XX para que se possa inferir sobre o objeto da tese, que por sua vez, é produtor de um conceito de História e tempo presente, muito antes de todas as formulações teórico-metodológicas institucionalizadas no Centre National de la Recherche Scientifique (CNRS), através do Institut d'histoire du temps présent (IHTP).

O estudo sobre Marx em termos temáticos é bastante vasto, entretanto, postulo que ainda há muito que se explorar da perspectiva teórica e metodológica esboçada por Marx em sua trajetória intelectual, ou ainda, uma chave para entender o tecido social.

\section{Sobre o conceito de história do tempo presente}

Sobre a história do tempo presente e a produção historiográfica desta perspectiva, a França apresenta uma das maiores referências. Em 1978, foi fundado o Institut d'histoire du temps présent (IHTP), efetivamente inaugurado em $1980 \mathrm{sob}$ a direção de Francis Bédarida, estendendo-se até o iniciar de 1990. A historicidade deste instituto é intimamente relacionada aos desdobramentos da Segunda Guerra Mundial e o surgimento de uma nova perspectiva historiográfica: o tempo presente diante da historiografia contemporânea.

Philippe Tétart, em uma edição propedêutica, intitulada "Pequena História dos Historiadores" (Petite Histoire des Historiens), publicada no Brasil pela EDUSC - Bauru - SP, nos apresenta uma síntese das perspectivas teórico metodológicas, e, sobre a história do tempo presente é enfático: “A história do tempo presente não é nova. Tucídides foi um historiador do vivido, e muitos outros o seguiram" (TÉTART, 2000, p. 133). E poderíamos acrescentar August Comte, Hegel, Ranke e Marx que também o foram.

\section{Filosofias da História e as grandes narrativas no século XIX}

Comte se preocupou com um tipo de História Universal ao propor seu "Curso de Filosofia Positiva" (Cours de Philosophie Positive). Com a lei dos três “estágios", 
pretende dar explicação e sentido ao processo histórico até o seu tempo presente. E certamente o faz. Uma teoria da história ganha expressão com Comte e, como pode se verificado é de grande importância para a sua própria superação diante de outras teorias da história. Comte está vinculado a uma visão ortodoxa da construção do conhecimento, calcando em sua teoria da história um devir evolutivo no sentido de contemplar o seu presente histórico. Possui também o caráter nacional, assim como quase todos os autores citados. A França de Comte é o modelo exemplar de estado positivo. A razão e os valores universais a partir da França deveriam ser tomados como o emblemático da civilização.

Comte possui um caráter político que expressa os interesses de uma classe socioeconômica ilustrada e que será exportada para outros países, como a Alemanha e mesmo posteriormente, o Brasil.

Da Prússia, Hegel está a vislumbrar todo esse processo, e provavelmente foi o primeiro pensador a captar o desenrolar da história em seu tempo presente, sobretudo sobre as revoluções burguesas na Europa Ocidental - com um novo patamar da história universal. Hegel, semelhante à Comte, também apresenta sua teoria da História. E o faz no mesmo estilo das grandes análises da História Universal, entretanto, o faz reabilitando a dialética para o seu tempo presente.

Para Hegel a Prússia teria atingido o seu estado maior de desenvolvimento e assim seria o paradigma universal da História. Seria possível aqui assinalar o caráter nacional presente em Hegel, e ainda, o germe da centralização política e do Estado Alemão.

Assim como Comte, Hegel (embora a existência de diferenças radicais sobre a História) está com os pés no tecido social da Europa. Fala a partir da Prússia, da monarquia, mas sonha com a República iluminista. Ambos, na França e na Prússia, se preocupam com o universal e o nacional a partir do posicionamento hegemônico do poder político de seu tempo presente.

Um pouco depois de Hegel, Leopold von Ranke, agora um historiador oficial do império prussiano, apresenta uma produção histórica bastante influenciada pelo pensamento nacional Alemão. Ele vivencia a centralização e criação política do Estado Alemão e vai escrever a história desse Estado. É também, considerado um dos grandes representantes do historicismo alemão. Este foi um período repleto de grandes explicações que destacavam os grandes personagens da história, reis, príncipes, papas, entre outros personagens. Um pensador vital para a germinação de sua própria antítese. 
Marx não procede diferente dos anteriores, no tocante à preocupação com uma História dos grandes períodos explicativos. Inicialmente, pode-se apresentar assustador para o pensamento doutrinado, entretanto, Marx não se exclui das grandes narrativas referidas anteriormente. Marx, todavia, possui singularidades em relação aos pensadores citados anteriormente. A começar pelo tecido social que é construído a sua perspectiva de História e tempo presente.

Assim, é nodal a distinção que apresento no projeto com fenomênica sutileza: História e tempo presente, e, história do tempo presente. A primeira se reporta as preocupações com a problematização do projeto da tese em relação ao presente como história em Marx. A segunda, se remete as perspectivas teórico-metodológicas, distantes de Marx por mais de um século. As duas perspectivas não são entendidas como sinônimas, do contrário entoaria uma canção anacrônica, de um Marx historiador (que nunca foi) e mesmo de um pesquisador institucional.

Marx compartilha, como muitos pensadores de seu tempo, das preocupações com a história e o tempo. Mas o faz de modo radicalmente distante da tradição universalista dos Estados nacionais europeus e os círculos intelectuais hegemônicos. Ele parte do prisma econômico para construir a sua concepção de História e tempo presente, baseando-se nos modos de produzir a vida durante a História, o que lhe coube, já no século XIX, o título equivocado de pensador economicista. Marx propõe entender a história do presente para se entender a história o capitalismo manifesto em seu presente imediato. Como cita em "Para a Crítica da Economia Política" (Zur Kritik der Politschen Ökonomie), publicada em 1859, quando do método da economia política:

\begin{abstract}
A anatomia do homem é $\mathrm{a}^{2}$ chave da anatomia do macaco. O que nas espécies animais inferiores indica uma forma superior, não pode, ao contrário, se compreendida senão quando se conhece a forma superior. A economia burguesa fornece a chave da economia antiga etc. Porém, não conforme o método dos economistas, que fazem desaparecer todas as diferenças históricas e vêem a forma burguesa em todas as formas de sociedade. Pode- se compreender o tributo, o dízimo, quando se compreende a renda territorial. Mas, não se deve identificá-los (MARX, 2008, p. 264).
\end{abstract}

É possível verificar o caráter de classe no pensamento de Marx quando é postulada a crítica à economia burguesa em seu tempo presente. Trata-se de um elemento singular da perspectiva histórica do autor diante de seu presente imediato, uma

\footnotetext{
${ }^{2}$ Nas traduções para as línguas portuguesa, francesa e espanhola, o artigo fora traduzido para o definido, sendo que a fonte na língua de origem apresenta o artigo indefinido, uma, o que é melhor expressivo da pluralidade de Marx ao entender que a anatomia do homem é uma chave para entender a anatomia do macaco, ou seja, as relações sociais do tempo presente é uma das possibilidades de se compreender a constituição histórica deste mesmo presente.
} 
característica inexistente em Comte, Ranke e mesmo em Hegel, onde se contemplava o tempo presente como o estado da realização humana através do estado positivo, da civilização. No caso de Hegel o encontro do ser "em si", "para si”, através do Estado como o mais alto grau de desenvolvimento histórico da humanidade, realizando-se em sua essência burguesa.

Durante a trajetória de Marx, buscar-se-á entender como se apresentou a sua perspectiva de história, ou mesmo a sua filosofia da História. Ainda a título de hipótese, é possível sustentar que em Marx o processo histórico possui o devir dos fenômenos, com avanços e recuos, diante de lutas de classes que em seu tempo presente se realizam na sociedade capitalista. Diferente de parte de seus contemporâneos, não há na crítica da economia política uma perspectiva de contemplação do tempo presente, ao contrário, a perspectiva de Marx é radicalmente crítica em relação ao seu presente imediato, consequentemente, o sendo também o seu conceito de História.

\section{Breve retour aos franceses}

Com essa breve digressão - iniciada por Philippe Tétard e complementada pela proposta da pesquisa -, ao referir-se a história do tempo presente não se faz detendo-a no século XX. Entretanto compartilha-se do entendimento que é no século XX que esta perspectiva ganhará um estatuto teórico e metodológico, sobretudo entre os historiadores profissionais.

O advento do Institut, ao propor o desenvolvimento de trabalhos historiográficos sobre a história do tempo presente, contou com a existência de olhares amistosos e sobretudo de olhares críticos entre os historiadores franceses, ligados a Nouvelle Histoire, emblematicamente Jacques Le Gof, em publicação realizada no mesmo ano de fundação do Institut d'histoire du temps présent em 1978. Vejamos a sua preocupação acerca da história e tempo presente:

A história do presente não raro é mais bem feita pelos sociólogos, os politicólogos, certos grandes jornalistas, do que por historiadores de ofício. Annie Kriegel, historiadora perspicaz e completa do fenômeno comunista, trocou a etiqueta de historiadora pela de socióloga (LE GOFF, 1995, p. 50$51)$.

Essas preocupações nos remetem a caracterização introdutória em história contemporânea, tempo presente e presente imediato. François Dosse, membro do Institut d'histoire du temps présent e com bastante trânsito entre os historiadores

\begin{tabular}{|l|l|l|l|l|}
\hline Revista Dialectus & Ano 1 & n. 2 & Janeiro-Junho 2013 & p. 40-49 \\
\hline
\end{tabular}


brasileiros, apresentou recentemente uma contribuição para se pensar a caracterização desses conceitos. Em entrevista cedida à revista História Agora (2007), François Dosse - pesquisador do Institut d'Histoire du Temps Présent (IHTP) e professor do IUFM de Créteil (Paris XII), esclarece sobre a história imediata e história do tempo presente:

Antes de falarmos sobre a História do Tempo Presente, vamos falar sobre a História Imediata. Estou me referindo efetivamente à contribuição de Jean Lacouture, na Nova Enciclopédia da História de 1978. Ele escreve um longo texto sobre a pertinência da História Imediata, que efetivamente é o ponto de

E continua: união do jornalismo e da história (DOSSE, 2007, p. 2).

\begin{abstract}
Então trata-se de saber qual é esta extensão, e é aí que estão as discussões sobre como o Tempo Presente aparece. Alguns dizem que a História do Tempo Presente se dá a partir da última catástrofe datada. Esta é uma maneira de definir o Tempo Presente.

Outros dizem que a História do Tempo Presente é entendida enquanto ainda existam pessoas vivas para transmitir sua experiência (DOSSE, 2007, p. 3).
\end{abstract}

Como aponta Dosse, o campo é complexo. A tradição francesa estipulou como História Contemporânea todos os fenômenos decorrentes do período após a Revolução Francesa até os nossos dias. Entretanto, esse balizamento se apresentou vasto por demais, dando margem para outras interpretações de contemporâneo.

Assim encontra-se a história do tempo presente, ligada a memória de gerações, traumáticas ou não, sobre determinados eventos históricos capazes de apresentarem o depoimento da memória diante de um tempo geracional, passível de estudos e interpretação históricas.

Concomitantemente, abre-se espaço para o que Dosse entende como história imediata. Esta, muito mais "quente", muito mais presente por se ocupar do cotidiano imediatamente construído, dividindo, o historiador, o mesmo espaço e tempo com o jornalista.

Ainda no final da década de 1970, parte dos trabalhos historiográficos se ocupavam de um tempo histórico mais recuado, principalmente a Idade Média, o que contribui para o entendimento das preocupações desses intelectuais com a história do tempo presente.

Henry Rousso, historiador também ligado ao I'HTTP, quando questionado sobre o que é a história do tempo presente, esclarece:

Para essa questão existem duas respostas. A primeira, uma resposta que se inscreve no contexto francês. Essa denominação está associada à criação deste instituto: o Instituto de História do Tempo Presente (IHTP) foi criado entre 1978 e 1980 e tinha por objetivo trabalhar sobre o passado próximo e sobre a História Contemporânea no sentido etimológico do termo, ou seja, uma História (...) na qual o historiador investiga um tempo que é o seu próprio tempo com testemunhas vivas e com uma memória que pode ser a

\begin{tabular}{|l|l|l|l|l|}
\hline Revista Dialectus & Ano 1 & n. 2 & Janeiro-Junho 2013 & p. 40-49 \\
\hline
\end{tabular}


sua. A partir de uma compreensão sobre uma época que não é simplesmente a compreensão de um passado distante, mas uma compreensão que vem de uma experiência da qual ele participa como todos os outros indivíduos (ROUSSO, 2009, p. 3).

Anterior ao ano de 1978, após a Segunda Guerra Mundial, passou-se ao desenvolvimento de uma prática historiográfica já consagrada, atualmente, como história do tempo presente, assim como postula Rousso na citação acima. Entretanto, as bases do que entendemos como história do tempo presente não foram forjadas sem maiores problemas, pois o tempo presente nos remete a uma série de problemáticas, as quais a historiografia, sobretudo a francesa, soubera administrar diante do desenvolvimento metodológico, tendo a fonte oral como privilegiada para tratar de uma História do Tempo Presente.

É diante deste contexto que também se encontra a perspectiva de história do tempo presente, e, diferente do que pode-se inferir, esta perspectiva, na década de 1970, não encontra muitos respaldos entre os annalistes dedicados a recuos históricos mais distantes do presente em que trabalha o historiador (como citado anteriormente as preocupações de Jacques Le Goff no ano de 1978).

Todavia, o autor do objeto da tese (Marx) em apresentação, parece se ocupar do tempo presente para a interpretação e desenvolvimento de uma concepção de História e tempo presente para além de seu tempo (1859), para além dos historiadores profissionais de sua época (principalmente da "escola" alemã), onde, a título de hipótese, necessita de provocar relações dialéticas entre as áreas do conhecimento, sobretudo da história, filosofia, economia e do que chamaríamos mais tarde de ciências sociais. Ainda sob a forma de hipótese, para Marx, o conjunto dessas ciências históricas é de elementar importância para o desenvolvimento de suas duas categorias centrais presentes em "Para a Crítica da Economia Política" de 1859: a História e o Tempo Presente.

\section{Colaborações sobre a História e Tempo Presente a partir do Brasil}

As contribuições sobre a história do tempo presente, a partir do I'HTP, colaborarão para demonstrar, na tese, que Marx, há mais de cem anos antes, também já se ocupava de forma central daquilo que formalmente só viera ganhar estatuto teórico e metodológico entre os historiadores profissionais a partir de meados do século XX, como a história do tempo presente. Todavia, ainda sob título de hipótese, Marx não o 
fizera a partir da academia, ao lado de historiadores, como existia em sua época. Porém, e, com efeito, desenvolvera uma prática teórica e metodológica onde a História e o tempo presente foram centrais na constituição de suas leituras sobre o processo histórico, a partir do presente. Vejamos a contribuição de Celso Frederico diante desta hipótese da tese:

Um dos eixos centrais da metodologia de Marx é a "centralidade do presente"
para o conhecimento dos fenômenos históricos. Com essa expressão, entende-
se a história como um processo em permanente desenvolvimento e o presente
como momento privilegiado para se entender o passado. É a anatomia do
homem que permite conhecer a anatomia do macaco - e não o contrário. É
também a existência do capitalismo plenamente consolidado que possibilita o
estudioso olhar para as sociedades pré-capitalistas e captar os sinais indicativos
da desintegração daquela formação social e anunciadores das possibilidades de
desenvolvimento futuro (FREDERICO, 2010, p. 7).

Deste modo não se trata, como ponto central da tese, de uma aplicação do conceito de história e tempo presente desenvolvido na França pós Marx, para a interpretação dos escritos de Marx. A tese trata de postular que Marx, em 1859 já havia desenvolvido o conceito de História e tempo presente durante a sua trajetória intelectual, antecedendose, de forma distinta, para mais de um século as preocupações teóricas e metodológicas acerca do tempo presente, emblematicamente expressas no decorrer do século XX. Busca-se, diante desta questão, até então hipotética, a percepção das categorias de História e tempo presente em Marx diante da singularidade destes conceitos que precedem uma longa e diversificada tradição diante da escrita da História. Entendendo que em "Para a Crítica da Economia Política" de 1859 é o trabalho iniciado por Marx, no momento de sua trajetória de maior experiência, e que terá sua continuidade em 1867 com a publicação de $O$ Capital, volume I. Nela, pode-se observar a permanência da centralidade da História como categoria teórica, forjada durante toda experiência de Marx diante de seu presente histórico.

Diante do contexto internacional de crise econômica e o retorno à Marx por parte dos analistas financeiros e especialistas ligados as ciência humanas, este autor pode contribuir para uma maior compreensão da economia política de nosso presente histórico socialmente situado diante da crise econômica do capital.

Acredita-se que a percepção do conceito de História e tempo presente em Marx e a sua contribuição para o debate atual, frente a conjuntura global, só pode ser executada com êxito diante da perspectiva de totalidade. Para isso torna-se imprescindível o diálogo amplo entre as questões culturais, a identidade socialmente constituída diante da 
memória e a economia, no sentido de serem elementos fundantes das relações de uma determinada paisagem histórica construída e em construção.

Nestes termos, a tese aqui possui pertinência temática e é congruente com problematizações já desenvolvidas nas ciências históricas a partir da produção intelectual brasileira, emblematicamente por José Carlos Reis, na Universidade Federal de Minas Gerais em 1987, com o tema "Marx e a História" (1987), sob orientação de Ivan Domingues. Trabalho esse também apresentado à Université catholique de Louvain, Bélgica. Esse trabalho dissertativo de José Carlos Reis é tributador de uma perspectiva de produção do conhecimento com base na totalidade dos fenômenos de seu tempo presente e busca em Marx as possibilidades de diálogos congruentes com as necessidades de seu tempo. Em "Marx e a História", o autor, assim como nesta proposta de tese, partilha da mesma perspectiva multidisciplinar entre as ciências históricas, uma vez que sua escrita e princípios teórico-metodológicos partem da historiografia, dialeticamente relacionada com a Sociologia e a Filosofia, esta última, abrigando a pesquisa em seu Programa de Pós-Graduação em Filosofia Contemporânea na década de 1980 .

Outros trabalhos mais recentes vão em um sentido de dialogar com Marx com objetivo de examinar fenômenos socioeconômicos e socioculturais nos anos 1990, como são os trabalhos desenvolvidos no Programa de Pós- Graduação da História da USP e doutorado em Filosofia do Instituto de Filosofia e Ciências Humanas da UNICAMP por Jorge Grespan, sobre “ $O$ conceito de crise em Marx na critica da economia política”, sob orientação de Marcos Lutz Muller, no ano de 1994.

\section{Considerações finais}

A pesquisa busca em Marx um conjunto de contribuições para o entendimento e transformação do presente como história imediata. Marx apenas não se preocupou em fazer suposições desalinhadas do conceito de totalidade histórica como também não se debruçou sobre crítica da economia política para apresentar exclusivamente uma interpretação da realidade, mas sim a transformação crítica, radical e revolucionária de seu tempo presente. Partimos de uma tradição que busca em Marx um conjunto de contribuições sobre o conceito de História e tempo presente. 
Essas duas categorias são intrinsecamente ligadas na produção marxiana acerca de sua crítica da economia política. O presente como História é parte fundante de toda obra de Marx, pois é a partir do presente que se pode ter acesso ao processo da História que se realiza no presente imediato. O presente imediato é a realização (ou não) do ser social e é nele que se pode encontrar uma das chaves de compressão das realizações do homem em sociedade.

\section{Referências Bibliográficas}

DOSSE, François. Entrevista. Por: Ana Carolina Fiuza. História Agora - Revista de História do Tempo Presente, n. 7, agosto de 2009.

ROUSSO, Henry. Entrevista. Por: AREND, Silvia Maria Fávero \& MACEDO, Fábio. Tempo e Argumento - Revista do Programa de Pós-Graduação em História. Universidade do Estado de Santa Catarina, Florianópolis, v. 1, n. 1, p. 201-216, jan./jun. 2009.

FREDERICO, Celso. "Nas trilhas da Emancipação". In: MARX, K. Contribuição à crítica da Filosofia do Direito de Hegel - Introdução/Karl Marx. Tradução de Lúcia Ehlers. 1.ed. São Paulo: Expressão Popular, 2010.

GRESPAN, Jorge. A Dinâmica da Crise. Um estudo sobre o conceito de crise na crítica de Marx à Economia Política. Doutorado em Filosofia, Universidade Estadual de Campinas, UNICAMP, 1994.

LE GOFF, Jacques. A história nova. São Paulo: Martins Fontes, 1995.

MARX, Karl. Contribuição à Crítica da Economia Política. São Paulo: Editora Expressão Popular, 2008.

. Zur Kritik der Politschen Ökonomie. Werke, v. 13. Erschienen 1859

bei Franz Duncker, Berlin.

.; ENGELS, Friedrich. A Ideologia Alemã I. Tradução de Conceição Jardim

e Eduardo Lúcio Nogueira. Lisboa, Presença; Brasil, Martins Fontes, 1974. (Coleção Síntase).

REIS, José Carlos. Marx e a História. Dissertação de mestrado em Filosofia Contemporânea. FAFICH, Universidade Federal de Minas Gerais, 1987.

TÉTARD, Philippe. Pequena história dos historiadores. Bauru: EDUSC, 2000.

\begin{tabular}{|l|l|l|l|l|}
\hline Revista Dialectus & Ano 1 & n. 2 & Janeiro-Junho 2013 & p. 40-49 \\
\hline
\end{tabular}

